\title{
Dança e Corporeidade: considerações fenomenológicas do espaço dançado e corpo percebido
}

\section{Marcelo de Maio Nascimento*}

Resumo

O presente estudo tem por objetivo investigar a dança em acepção filosófica, mais especificamente, a corporeidade. O caminho eleito incide na abordagem de teorias da espacialidade desde a filosofia clássica de Platão e Aristóteles até a fenomenologia existencialista de Merleau-Ponty. A reflexão parte do princípio que a corporeidade se processa no balanço de experiências acumuladas pelo corpo e pensamento em dois espaços: o espaço existencial, antropológico ou vivido e o espaço natural, aquele idealizado geometricamente, objetivado pela percepção. Neste contexto, aspectos de ordem fisiológica, biológica, funcional, psicológica e cultural desempenham papel no processamento dos dados de uma corporeidade. Ao focalizar a temática "Dança e Corporeidade", busca-se contribuir para o ganho de conhecimentos desta matéria, neste sentido, a questão também versa sobre a epistemologia da dança.

Palavras-chave: Corpo. Corporeidade. Dança. Filosofia da Dança.
Abstract

The present study aims to investigate dance in philosophical sense, more specifically, the corporeality. The path chosen approach focuses on theories of spatiality from the classical philosophy of Plato and Aristotle to the existential phenomenology of Merleau-Ponty. The reflection assumes that corporeality is processed in the balance of experiences accumulated by the body and mind in two spaces: the space existential, anthropological or living space and the natural espace, that geometrically idealized, objectified by perception. In this context, aspects related to physiological, biological, functional, psychological and cultural play a role in the processing of data of a corporeality. By focusing on the theme "Dance and Embodiment", seeks to contribute to gain knowledge of this subject, in this sense, the question also concerns the epistemology of dance.

Keywords: Body. Corporeality. Dance. Philosophy of Dance. 


\section{Introdução}

"A área circundante é dedicada à experiência do corpo. O espaço também é experimentado fisicamente. Nós o adentramos. Vemos então este espaço próprio ante nós. Nós o percebemos pelo fluxo do ar, ouvimos os sons vindos de todas as direções, também sentimos o mesmo espaço ao lado e atrás de nós, contudo, sem vê-lo diretamente" (WESTPHAL 2008, p. 46).

De acordo com a Física, o termo corpo se refere ao objeto retentor de massa e titular de um determinado espaço. Assim sendo, dois corpos não podem ocupar o mesmo lugar no espaço, ao mesmo tempo - princípio da impenetrabilidade -, além de que um corpo não pode ocupar, ao mesmo tempo, dois lugares no espaço. Por outro lado, em sentido fenomenológico, o corpo que dança é espaço, território à transcendência do sujeito, o que lhe aproxima às fatalidades do ambiente: artifício à união do "ser-no-mundo".

O juízo desenvolvido pelo sujeito sobre aspectos de seu corpo pode ser compreendido como corporeidade. Neste entendimento, a corporeidade incide, entre outros, em processamento de experiências - vivências - acumuladas pelo corpo, ao longo dos anos, ou seja: um arranjo de conhecimentos subjetivos, também amparado pela capacidade motriz humana. No caso do sujeito que dança, a corporeidade sucede da cognição de variáveis anatômicas, cinésiológicas, fisiológicas, culturais, sociais e emocionais. Assim, contrariamente ao senso comum, na dança unimos o corpo ao pensamento e, desta forma, o pensamento da dança se torna ele mesmo uma dança pensante (ALÁRCON, 2009). A construção desta biografia corporal sobrevém da performance rítmica e sinergética entre músculos, tendões, ligamentos, articulações e, principalmente, da pele. Tais artifícios se afiguram como instrumentos à captação e incorporação de informações presentes no entorno do sujeito. Considerando que o corpo é cercado por múltiplas informações (dados), então, haverá momentos em que elas estarão próximas a ele, já em outras circunstâncias, distantes. Diante disto surge a necessidade de que o sujeito por meio dos segmentos corporais - se afaste ou aproxime de objetos e pessoas. Com o movimento - ambulo - o homem alicerça seu vínculo - diálogos - com pessoas e coisas: uma condição ao firmamento do "ser-no-mundo", também definido por HEIDEGGER (2006) como “Dasein". Prontamente, é com o auxilio do aparelho locomotor, engrandecido por suas habilidades funcionais que o homem irá processar os dados captados do ambiente, construindo assim um conjunto próprio de saberes. Tais conhecimentos são ratificados ou retificados, diariamente, por meio da exteriorização de intenções do sujeito junto ao social. Vale ressaltar que muitas dessas ações são categóricas à sobrevivência do próprio sujeito e espécie.

Dança e Corporeidade, temáticas amplas de considerações, ricas de sentidos e interpretações. O presente estudo tem por fim criar um espaço à reflexão dos juízos estabelecidos pelo "eu-interior" do sujeito que dança em relação ao seu próprio corpo. O caminho eleito incide na abordagem de teorias do espaço e do corpo em acepção filosófica. A atitude reflexiva aqui proposta 
se fundamenta em uma jovem disciplina, a Filosofia da Dança (ALARCÓN, 2009; FISCHER; ALARCÓN, 2006), a qual possui representatividade junto a Ciência da Dança (BRADSTETTER; KLEIN, 2007, JUNG, 1990; ARTUS, 1993). Neste contexto, entende-se que ao exercitar o pensamento em sentido às dimensões do corpo, isto nos aproximará um pouco mais sobre o quê da dança. Prontamente, é por meio do arranjo de pensamentos que esta investigação busca contribuir para o desenvolvimento de uma epistemologia da dança, ou seja, garantir o ganho de seus conhecimentos, visto que: "(...) não importa mostrar o que é o conhecimento da dança, mas o porquê do conhecimento: como sabemos o que sabemos sobre a dança?" (KLEIN, 2007, p. 27).

\section{A espacialidade: concepções históricas e filosóficas}

Considerando, que o espaço é visto pelo homem como algo próximo e ao mesmo tempo distante, há momentos em que ele nos é intimo, apresentando-se alheio em outros. Assim, ao longo dos anos, criaram-se distintas formas para pensar o espaço. Na obra "Fragmento da Natureza", por exemplo, Goethe concebe poesia à relação homem-espaço, dizendo: "Estamos cercados e abraçados por ele, incapazes de entrar mais fundo nele próprio. Sem convite e aviso, ele nos leva para dentro do círculo de sua dança e se afasta de nós (...). Vivemos dentro dele, mas somos estranhos a ele" (GOETHE, 1982, p. 22).

Optamos por iniciar a abordagem da espacialidade com Platão (428-348 a.C), já que foi ele o primeiro filósofo a versar sobre o espaço de forma sistemática, atribuindo-lhe nome e natureza. Tais considerações foram instituídas em diálogos como Timaios, Filebo, Sofistas e Politeia, os quais exibiam caráter astronômico, buscando explicações para a essência do mundo e existência do homem sobre ele. No entanto, é com Aristóteles, aluno de Platão, que encontramos indícios à formulação de uma teoria do espaço dançado e corpo percebido. Aristóteles valorizava as experiências pessoais, em sua visão a simples coleta de dados por meio da linguagem não seria suficiente à construção de teorias. Assim sendo, o filósofo não se satisfez com as abordagens espaciais de seu mestre Platão.

Segundo Schulbert (1987), a filosofia aristotélica veio iluminar a construção dos pilares da teoria espacial, principalmente, ao estabelecer duas questões: É o espaço algo real e o que é ele? Sendo que a segunda pergunta concebe - ainda - mais complexidade ao caso: Existe um vazio, algo sem fronteiras, ou seja, o espaço infinito? Deve-se salientar que a ideia do espaço infinito elimina a presença de todo e qualquer tipo de objeto ou substância na reflexão, pois a existência de tal item delimitaria o ambiente, instituindo fronteiras dentro do próprio pensamento.

A discussão do espaço aristotélico inicia com a diferenciação entre "localidade" e "espacialidade". No senso comum, os dois termos embolsam sentido equivalente, entretanto, na concepção aristotélica há diferenças entre local e espaço. Assim, partindo do pressuposto de que cada elemento da 
natureza - ar, fogo, água e terra - possui um território específico e desde que não haja movimento, não haverá invasão entre seus espaços, o filósofo da experiência elege "corpo" e "movimento" como elementos palpáveis à constatação do fato (espacialidade). Aristóteles atribuiu ao movimento valor à gênese do "local/lugar", condicionando a isto - ainda - três elementos: espaço (topos), vazio (kenon) e tempo (chronos).

Neste momento, gostaríamos de fazer uma analogia entre a obra de Rudolf von Laban e a visão aristotélica da espacialidade. Em sua epistemologia da dança, Laban incorpora princípios como "topos", "kenon" e "chronos" para chegar ao entendimento da movimentação corporal segundo planos espaciais. Na obra "The Mastery of Movement on the Stage" escrita em 1950, Laban principia a estruturação de uma metodologia para o trabalho coreográfico de palco, desenvolvendo, inclusive, terminologias próprias. De tal forma, ele é considerado como um dos precursores do estudo da dança em caráter científico (ULLMANN, 1978). Seu trabalho abriu espaço à compreensão da dança como campo próprio de conhecimentos, principalmente, sob a forma textual (Labanotação). A obra de Laban também influenciou a criação de outras metodologias de estudo da movimentação corporal, como o processo do "Movent Evaluation Graphics" (MEG) e uma resultante deste ponto de vista, o método "Kestenberg" (IVB).

Ora, retornando a discussão a Aristóteles, mais especificamente aos conceitos localidade e espacialidade, segundo Immendörfer (2005), o filósofo define "movimento" como o agente da circunstância responsável pelo deslocamento de corpos de um dado lugar para o outro. Assim, o local é reconhecido como a quantidade que permanece constante. Prontamente, movimento e local são correlatos. Para trabalhar a quantidade (local) Aristóteles busca auxílio nos segmentos corporais, os quais, segundo ele, estabelecem a afinidade entre as partes. Seu raciocínio parte do princípio, que tal qual o fogo, a água, a terra e o ar, cada segmento corporal ocupa um lugar/local reservado, onde a quantidade de suas partes permanece constante, não existindo colisão entre elas, desde que não ocorra movimento intencional ${ }^{1}$.

É importante frisar que Aristóteles reconhece o local como um acidente de existência real, entretanto, não em sentido a substância, ou seja, um ser independente, excluindo da "continuidade deste mesmo local" a possibilidade de esvaziamento (IMMENDÖRFER, 2005). Ora, tendo em vista títulos aristotélicos, tais como continuidade e descontinuidade, limites corporais, vazio, substância, movimento e estando eles associados à apropriação e processamento de experiências pelo corpo/eu, consideramos que esta faceta da teoria espacial aristotélica pode colaborar no entendimento da consciência do corpo que dança.

Contudo, não podemos embaralhar os acontecimentos ou, mesmo, confundir os temos "localização" com "corpo", visto que representam coisas diferentes, além de serem constituídos por naturezas distintas. A reflexão parte do principio que não seria possível haver movimento caso substância 
e forma coincidissem, porque enquanto o espaço permanece inerte, o corpo presente nele se movimenta. $E$, isto vem auxiliar o pensamento humana na formação da ideia espacial. Por outro lado, em sentido à concepção fenomenológica, corpo e espaço se vinculam, constituindo-se em "fundante" e "fundado". Nesta visão, corpo e espaço representam dois em um, elementos à vivência dos fenômenos (MERLEAU-PONTY, 1965). Segundo Ponty, além da distância física e geométrica que existe entre mim e as coisas do mundo, há uma distância vivida, a qual me liga às coisas que relatam fatos reais para o meu "eu". DUPOND (2010) refere-se a esta forma do corpo pontyano da seguinte forma:

(...) é a potência de se juntar as coisas e de se sincronizar com elas; (...) é um sistema sinergético cujas funções estão todas unidas no movimento geral do ser no mundo; (...) é o lugar, ou antes, a atualidade do Fenômeno de expressão; (...) ele faz o tempo em lugar de padecê-lo (p. 13).

Referências diretas sobre a ação dos órgãos do sentimento (aesthesie) à determinação do espaço não são abundantes na obra de Aristóteles. Contudo, o filósofo não deixa duvidas de que o espaço consiste em uma noção perceptível do homem, instituída a partir de princípios corporais (IMMENDÖRFER, 2005). Alusões diretas sobre a participação de órgãos do corpo humano à captação de dados sensíveis passam a vigorar na ciência com o ingresso de experimentos práticos em procedimentos investigatórios. Este período da ciência é caracterizado pela busca de uma sabedoria firmada na verificação comprovada, empírica e racional.

\section{A espacialidade, do racionalismo ao empirismo}

Como não poderia deixar de ser, a teoria espacial aristotélica recebeu críticas, determinando reajustes em suas definições, o que, por outro lado, concebeu avanços à compreensão da temática. O fato encontra fundamento na ambiguidade que é traduzida como ação interpretativa do filósofo, um apelo para que a investigação da própria interrogação persista. Para o filósofo, ambiguidade é tema próprio e questão inerente ao processo, contribuindo à fundamentação de certezas, sem pô-las em causa. No entanto, é necessário diferenciar entre a boa e a má ambiguidade (CUNHA, 1992).

O aprimoramento das teorias espaciais foi assinalado, ao longo dos anos, essencialmente pela matemática, física e metafísica. Tais disciplinas serviam como instrumento à materialização de pontos de vista próprios do período histórico vigente, os quais, por conseguinte, determinaram as chamadas correntes do pensamento. O racionalismo, por exemplo, é considerado como uma corrente ou projeto filosófico, surgido no século XVI e ainda hoje presente, que valoriza o pensamento lógico. Na compreensão racional da época a espacialidade possuía duas naturezas: na primeira, o espaço era vis- 
to como um sistema fechado, portanto, finito; enquanto na segunda ele era infinitamente estendido, concebível, somente, por meio do pensamento.

Como resultado disso, surgiram duas teorias direcionadas em desvendar se o espaço seria uma produção sensorial, instituído por meio da percepção ou um produto lógico, circunscrito na matemática.

Em sentido ao pensamento lógico, René Descartes (1596-1650) é considerado o seu principal idealizador (cogito er sum, penso logo existo). Descartes foi o construtor de uma metodologia inovadora para a época, fundamentada no principio de certezas inabaláveis (COTTINGHAM, 1993). A lógica do pensamento cartesiano pode ser resumida da seguinte forma: a) a certeza está no pensamento e não na experiência sentida; e, b) a garantia para tanto reside em Deus. Assim sendo, além de testemunhar que a veracidade só poderia ser atingida por meio da matemática ou da geometria, sua teoria seria infalível, pois se fundamentava na fé do criador: Deus. Segundo o pensamento cartesiano, a legitimação do conhecimento sucede da instrumentalização que tem por fim verificar as variáveis e validar o conhecimento. Neste sentido, introduz-se o emprego de balanças, termômetros, relógios e fórmulas aritméticas na observação e constatação dos fenômenos.

É importante ressaltar que em sentido ao estudo do corpo, René Descartes não desconsiderava a intima relação deste com o movimento. Entretanto, ele se referia ao corpo como aquilo que pode ser transferido de uma só vez (simul transfertur). Assim, subentendesse que o cartesianismo reduz o movimento à função de principio de alteração de massa no espaço, ou seja, "momento externo de modificação da matéria", atribuindo a ele, entretanto, a acepção de um predicado do corpo (motus nihil aliud est materia mota, modo eius quam). Para Immendörfer (2005) a deficiência desta teoria reside na ausência de um sistema de referência constante à obtenção do movimento. Um debate e resoluções para tal assunto surgiria, mais tarde, com a teoria do espaço absoluto proposta por Isaac Newton (1642-1727).

No que tange à relação entre a percepção e a espacialidade, é a partir do empirismo que esta temática viria a ganhar ênfase. A visão empírica do conhecimento é encontrada, em particular, na filosofia inglesa, em especial nas obras de Francis Bacon (1561 -1626), Thomas Hobbes (1588-1679), John Locke (1632-1704), George Berkeley (1685 -1753) e David Hume (1711-1776). Nesta concepção, o mundo natural tanto é observado, como examinado. Prontamente, o conhecimento não surge a priori, ou seja, teorias e hipóteses devem ser testadas. Com o advento das técnicas empíricas, a psicologia perceptual, por exemplo, amplia suas dimensões, estabelecendo teorias inovadoras como no caso da determinação da espacialidade pelos sentidos. Assim sendo, atribuiu-se importância ao "ponto de vista", ou seja, a localização do sujeito no espaço, frente ao esclarecimento de mudanças perceptíveis do ambiente. No âmago da questão há o intuito de compreender os fenômenos, os quais devido ao fator "virtualidade" se apresentam, muitas vezes, turvados à percepção humana.

YOKO (1995), referindo-se ao espaço em analogia a visão transcendental kantiana, salienta: "O espaço é a maneira pela qual nós representamos as 
coisas que nos foram dadas no sentido exterior, ou seja, é a condição sob a qual podemos ter experiência coerente de coisas fora de nós" (p. 3). Segundo Kant, é possível referenciar o espaço e as coisas extensas, entretanto, unicamente a partir do ponto de vista humano. A autora complementa: “(...) afastar-se da condição subjetiva, sob a qual só podemos ter a intuição externa à representação do espaço significa nada" (p. 3).

\section{Espacialidade e corporeidade entre "cogito" e "Leib"}

Para o matemático grego Euclides (360 a.C - 280 a.C.) o espaço é tridimensional. Esta forma de entender a espacialidade atribui à subjetividade valor à instauração do fato, tornando o espaço relacional, ou seja, admitindo a extensão dos objetos - res extensa -, artifício este imprescindível à materialização de uma "res cogitan" (juízo, pensamento). Ao assumir a subjetividade como ferramenta à noção ou constatação do espaço, pondera-se, igualmente, a perspectiva - posição ou ângulo - assumida por cada pessoa no ambiente. Segundo Hermann (1996), é na percepção do objeto que a ideia espacial se forma. No caso da dança, por exemplo, o juízo formado pelo coreógrafo, dançarino ou público sobre uma dada cena, gesto ou movimento apresentado no palco, nunca será igual entre esses sujeitos, visto que o processamento de sons e imagens é relativo às suas perspectivas.

No pensamento cartesiano, o espaço existia como modelo básico à ordem. Assim, processos físicos atuavam dentro do "contorno", uma espécie de "container" para a matéria e seus campos. Com Descartes se instaura a concepção dualística entre sujeito e objeto, o que, por conseguinte, motivaria a filosofia a criar o conceito "Leib", palavra alemã, cuja tradução - também significa corpo. Assim sendo, no modelo cartesiano, o sujeito não reflete sobre a seu corpo, quem pensa é o seu "eu" sob a forma de um "res cogitans", o qual se diferencia e ao mesmo tempo distancia do "Leib".

Com localização entre o espírito e o corpo-carnal, o "Leib" diz respeito ao território destinado à reflexão e entendimento do corpo vivido ou percebido. Durante a organização sinestésica é ele, por exemplo, quem assume o comando da ação, o "Leib" é o receptor de sensações vividas pelo corpo físico (ALARCÓN, 2009), agente da "res extensa". Diante disto, a materialização do corpo pensante se processa na dimensão do "Leib" e não no cérebro. $E$, por falar em dimensão, a ideia de um "Leib" concebe para dança margens à imaginação de uma quarta dimensão, locada não ao lado, a cima ou ao fundo de quem dança, porém sim encarnada e incorporada. Tal projeção denotaria a dimensão da experiência vivida pelo corpo em si mesmo.

No entanto, quando a questão incide na vivência (incorporação e encarne) da dança há, ainda, dois itens a considerar: o quantitativo e qualitativo de experiências acumuladas pelo corpo e mente de quem dança. Durante a ação dançada, o sujeito entra em contato com um infindável número de informações que lhe induzem a refletir sobre si mesmo e o entorno. Assim, é mediante o emprego de giros, passos, saltos, gestos, em adequação aos ritmos e, 
por meio de percepções visuais e auditivas que a corporeidade de quem dança vai se constituindo.

Ao vivenciar os códigos ritualísticos impressos em festas e cerimonias e, no caso da dança de palco, ao entrar em contato com a iluminação, a textura de cores do cenário, a música e os aplausos do público, o sujeito dançante vai materializando sua corporeidade em número e qualidade. De tal forma, uma investigação da dança/dançar nos perímetros da filosofia da percepção consiste em tarefa ampla de contextos, o que nos motiva a conduzir a seguinte reflexão: Qual a diferença sensorial entre o espaço (topos) dançado e o não dançado (kenon)? E, onde estariam eles, dentro ou fora do corpo? E, quanto ao tempo (chronos), qual seria a sua relação e impacto à gênese de uma corporeidade?

Ora, sabendo que a corporeidade se afirma como território de conhecimentos pessoais, jurisdição, onde impressões do corpo/sujeito são sucessivamente arquivadas, e, sabendo, ainda, que o tempo é elemento à organização de experiências sob a forma de raia ou sequência, então, deve-se convir que: além da relação "corpo-espaço-movimento", a tríade "corpo-tempo-movimento" também imprime valor ao processamento de uma corporeidade. Isto significa dizer que a conscientização de corpo ou, melhor dizendo, de nossos corpos (identidade), seja vista da perspectiva estética, laboral, erótica, funcional, sexual, familiar, social, artística, educacional ou de saúde, a ideia de corpo se ordena cronologicamente. Ou seja, o corpo se define e autorregula, entre outros, por intermédio dos desafios impostos pelas vicissitudes da vida. Hetzel (2011) salienta:

O tempo é a experiência de criação e a infração das coisas. Esta experiência só é possível a partir da condição da memória humana, pela crença na estabilidade das coisas e em uma, pelo menos, relativa continuidade de nossa própria existência, no entanto, também, pela capacidade de esquecer (p.93).

É por meio da percepção corporal do ontem, do agora e o do amanhã que o corpo real ou idealizado se torna mais próximo ou distante de cada um. A temporalidade consiste em modelo de organização interna do sujeito, auxiliar do arranjo de saberes próprios da pessoa, até mesmo do tema corpo. Ao dançar o sujeito vai idealizando conhecimentos que são agregados a sua biografia, auxiliares diretos no processamento de seu autoconceito/autoimagem e autoestima (NASCIMENTO, 2007); neste caso estamos nos referenciando ao termo identidade. No entanto, vale ressaltar que o processo de identidade e corporeidade não se dissocia de mecanismos "neurosensoriais" e "neurobiológicos".

Reinchenbachs et al (2006) destacam que ao se negar a dissociação entre espaço e tempo abriu-se um novo campo de estudo e discussão científica. Nas obras de Newton, por exemplo, encontramos a definição de tempo como período necessário ao deslocamento entre $A-B$, já para Kant ele é elemento organizador do "eu" interior. Pressupostos dessa ordem evocam litígios "bio- 
físicos" e "fenomenológicos". Assim sendo, com base na figura que segue, formamos os seguintes questionamentos: Sucedido o tempo, o espaço permanece inalterado? Ou, ele se transforma?

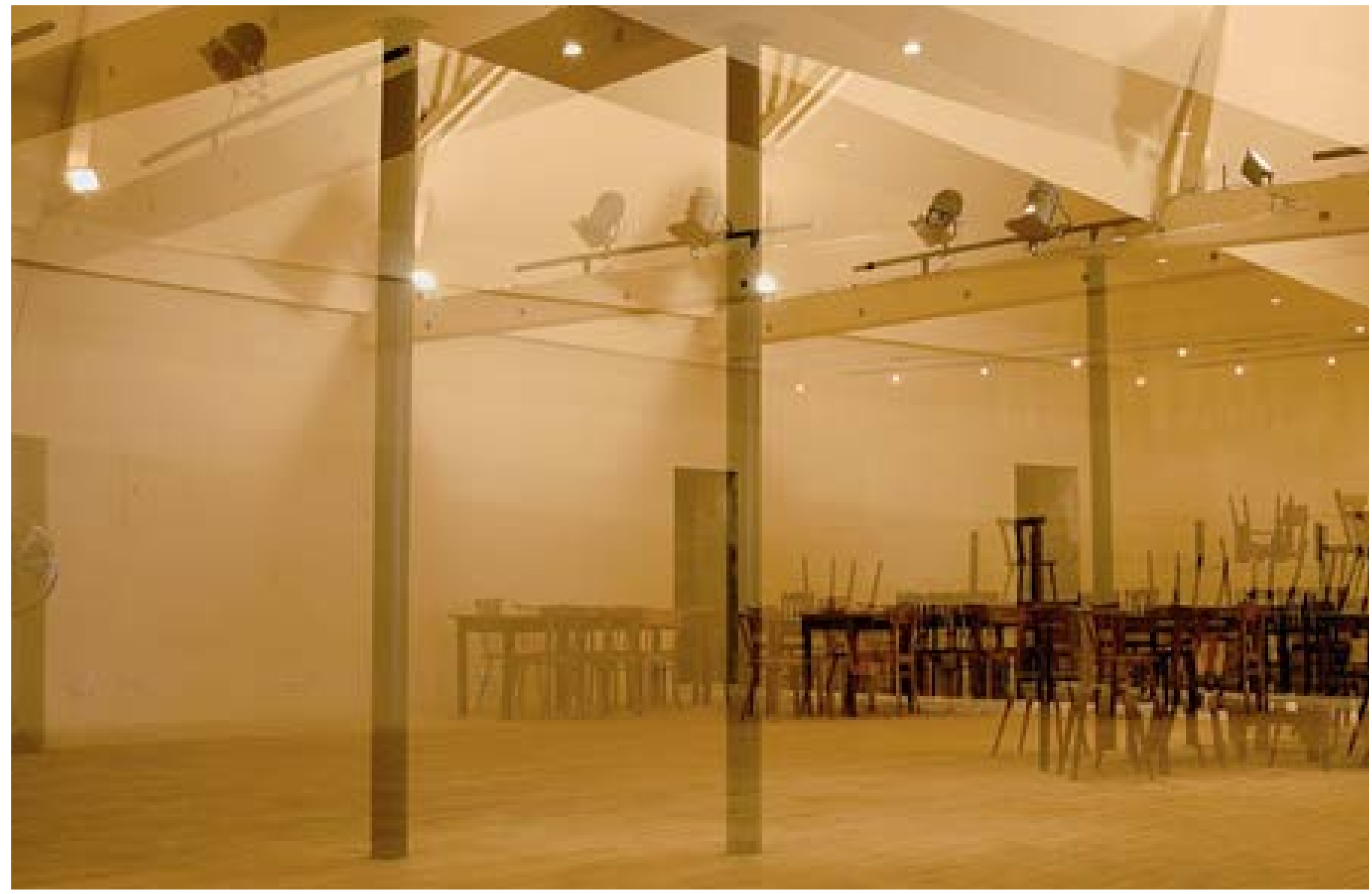

Fig. 1: Café Ada, Wüppertal/Alemanha, 2006.

(Autora: Zerrin Aydin-Herwegh)

E, se considerarmos uma dada composição coreográfica como matéria (res extensa), o que decorre ao longo do tempo? Corpo e coreografia permanecem idênticos ou modificam suas identidades? Verdade é que na dança nem um movimento é igual ao outro e, mesmo com toda técnica, ensaio e competência jamais haverá exatidão na repetição do mesmo gesto, figura ou coreografia. A unicidade do movimento é intrínseca ao protagonista e singular em tempo e espaço. Mas a reflexão segue: $E$, quanto ao espaço fenomenológico, como e onde ele é percebido no corpo? De onde vêm e para onde vão tais sensações? Qual o papel do corpo nesta circunstância? Com o propósito de contextualizar tais ambiguidades surge a seção seguinte, a qual traçará afinidades entre a dança/dançar com aspectos anatômicos, fisiológicos e biofísicos do homem. 


\section{O espaço fenomenológico - corporeidade - na dança}

Segundo Günzel (2007), a visão tridimensional do espaço instigou a criação de diferentes pautas sobre a espacialidade, principalmente, no campo filosófico. No principio dos tempos a noção espacial era basicamente intuí$\mathrm{da}$, então, armazenada e a seguir reproduzida sob a forma de lembranças. A seguir, em momento oportuno, ela era ressuscitada com o objetivo de identificar algo, gerando por fim o sentido da espacialidade. Contudo, qual seria a repercussão disto à dança? Se considerarmos, por exemplo, que durante o ensaio de uma determinada coreografia a pessoa que dança acumula e adéqua perceptivamente centenas de informações, concluímos que para cada gesto ou movimento estudado, uma nova noção espaço-temporal será codificada. Tal processo apresenta princípios físico-perceptíveis e cognitivos (assimilação e acomodação), ou seja, na dança o processamento das vivências corporais é estabelecido, sobretudo, pela associação entre conhecimentos pré-existentes na memória do movimento e informações, recentemente, apreendidas pelo sistema neural e funcional.

O palco à construção e consciência de uma corporeidade ou de um "eu-dança" reside, como já foi dito, entre outros, na intensidade dos estímulos vivenciados pelo sujeito. Isto significa dizer que a relação entre a magnitude do estímulo da dança, bem como o número de experiências que o sujeito acumula, contribui à edificação da ideia de corpo. Fatos dessa ordem nos conduzem a uma interessante reflexão: se compararmos, por exemplo, um sujeito que dança profissionalmente com outro que dança em seu tempo livre ou, mesmo, aquele que não dança, como se processam e apresentam suas corporeidades?

Pois bem, no caso do dançarino profissional, este é detentor de um elevado número de horas de movimentação corporal. Prontamente, o processamento de sua corporeidade é garantido pela magnitude de suas experiências, além de existir o engrandecido do processo por meio de suas habilidades técnicas de dança, as quais funcionam como ferramentas calibradas à captação de dados. Neste contexto, a técnica de dança não pode ser considerada como um instrumento disciplinador (Foucault) ou civilizador (Elias) do corpo, mas sim como facilitador à apreensão de informações. Toda a técnica de dança qualifica os segmentos corporais, permitindo que corpo/sujeito criem e assumam, cada vez mais, posições ou ângulos no ambiente, com maior eficiência e menor gasto energético. Disto concluímos que, quanto mais rica for a técnica da pessoa que dança, tanto maior serão suas chances de ensaiar o mundo e o próprio corpo, segundo planos, direções, sentidos e ritmos.

No caso do sujeito que dança como forma de lazer ou, mesmo, aquele que não dança, não é possível afirmar que sua corporeidade seja baixa ou deficiente; visto que isto não existe. Esta pessoa detém, com certeza, muitas outras aptidões corporais que mesmo não sendo específicas da movimentação ritmada, são elas, indiscutivelmente, estimas de uma corporeidade. Corporeidade não significa talento esportivo, artístico ou estético. A corporeidade é conhecimento próprio de cada "individuo", estabelecida de acordo com seus 
arquétipos funcionais, sociais, psicológicos, culturais, entre outros. No entanto, uma possível afirmação sobre a diferença entre a corporeidade do sujeito que dança profissionalmente e os demais, diz respeito ao termo "autoconceito ou autoimagem do movimento" (QUITTEN, 1994).

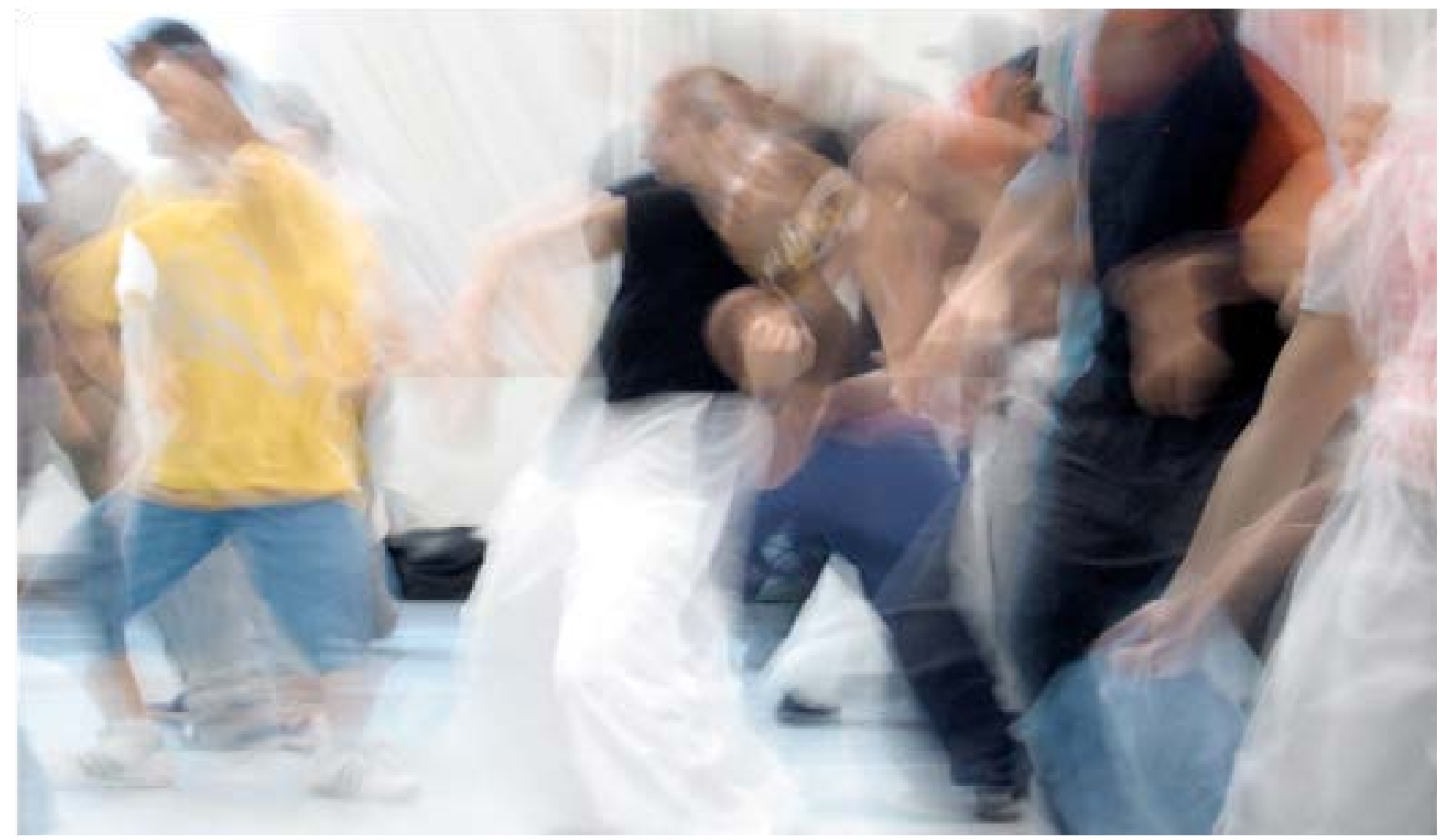

Fig. 2: Hipo-Hop, Tanz Haus NRW/Düsseldorf, 2006.

(Autora: Zerrin Aydin-Herwegh)

O termo autoconceito ou autoimagem do movimento significa juízo próprio de consciência do movimento (QUITTEN, 1994). Ele congrega uma série de itens que representam os saberes de uma pessoa sobre o "próprio corpo", ou seja: consiste em mais uma dimensão psicológica do "eu-corpo". O autoconceito do movimento funciona como um sistema de consideração de valores essenciais à consolidação da corporeidade e, portanto, do "eu" "corpo que dança". Assim, considerando, que somos sujeitos híbridos de identidades, o autoconceito ou autoimagem do movimento vem somar no processamento estrutural do "eu-identidade".

\section{Limitações do espaço corporal}

Limitações espaciais são fronteiras encontradas, geralmente, em construções arquitetônicas com a finalidade de balizar as interações humanas (IMMENDÖRFER, 2005). Considerando, o espaço absoluto - Newton - des- 
provido de fronteiras como habitat humano, surge um questionamento: Como seria viver no espaço infinito? Com certeza, extremamente cansativo e desorientador. Por este motivo é que limitamos o espaço, facilitando assim nossa maneira de perceber e diferenciar os ambientes. Tal iniciativa equilibra a existência humana, direcionando melhor nossa atenção aos objetos.

$\mathrm{E}$, quando o tema diz respeito às fronteiras, há de se convir que o exemplo mais próximo a nós incide no tecido que reveste o corpo. A pele compreende o limite entre dois mundos, anfiteatro de sensibilidades, zona onde impressões como calor, frio ou dor, importantes na primeira infância são reguladas e aprendidas. Toda a experiência vivida na pele é real, funcionando como código útil ao estabelecimento de uma corporeidade. Vale salientar que é também na pele que vivenciamos os múltiplos indicadores socioculturais, tal processo também pode ser definido como "embodiment" (MERLEAU-PONTY, 1966; BORDIEU, 2003; CSORDAS, 1994).

Em sua "Fenomenologia da percepção", Merleau-Ponty faz uma clara distinção entre o espaço da noite ou do mito e o espaço natural. A primeira forma do espaço é existencial, consiste no ambiente reservado ao envolvimento, aquele em que sujeito e objeto se encontram, onde solidariedades do homem com o mundo são ensaiadas. Tal concepção apresenta fortes laços com as ideias de Heidegger expostas em "Ser e tempo" (Sein und Zeit). Do outro lado, há o espaço "natural" ou espaço de percepção, algo real, singular e objetivo, o ambiente idealizado geometricamente. Vale ressaltar que cada um desses espaços é para o outro fundante e fundado (DUPOND, 2010). Assim sendo, o espaço existencial funda o natural, visto que o primeiro materializa (res extensa) as idealizações cogitadas pelo segundo. Contudo, para que tais processos se efetivem necessitamos de mediadores que captem e transmitam as informações incrustadas no espaço existencial. $E$, quem seriam eles no contexto da dança?

Ao dançar, empregamos músculos, tendões, articulações, além de receptores proprioceptivos que são ativados ininterruptamente. Prontamente, no dançar, há esforço, tensão, uma constante processual de adaptações neuromusculares, cardiovasculares, respiratórias e neuroendócrinas que, não obstante, integram o coeficiente da consciência corporal que é variável. A capacidade humana de perceber distintas partes do corpo é chamada de "somestesia" (do latim "soma", que significa corpo e "aesthesie", percepção). A "somestesia" consiste em modalidade sensorial formada por diversas "submodalidades" como tato, termoregulação, dor e propriocepção.

O sistema "somestésico" representa uma cadeia sequencial de neurônios, fibras nervosas e sinapses que traduzem e codificam informações vivenciadas pelo corpo (LENT, 2010). Dividido em três subsistemas, o "exteroceptivo" é o primeiro, rápido, preciso e útil ao detalhamento da imagem espacial e da superfície corporal; sua principal "submodalidade" é o tato. O proprioceptivo é o segundo subsistema, presente em músculos e articulações, também é veloz, é quem informa ao cérebro a localização dos segmentos do corpo no espaço. Já o ultimo é o "interseptivo", o qual transmite noções funcionais do corpo, materializando sensações gerais de um bem ou mal estar, como por 
exemplo, o metabolismo dos órgãos ou o sentido da dor.

A categorização do sistema sensorial é anatômica, instituída de acordo com a localização de células ou de prolongamentos responsáveis pela receptação de estímulos. Os mesmos estão restritos a tecidos específicos, tais como o sistema visual, auditivo, gustativo, vestibular e olfativo (CURl; PROCOPIO, 2009). Nesta perspectiva, é na experiência sensório-motora (dança) que a experiência estética - atributo à corporeidade - se institui. Mas o que é estético na experiência de uma dança? $\mathrm{E}$, qual a diferença entre a experiência estética e a não estética?

A experiência estética é entendida como o estimulo sensorial diretamente ligado à causa que liberará um elemento surpresa. Tal surpresa trará consequências, ou seja, ela será responsável pela correção de informações preexistentes ou pela consubstanciação do novo. Assim, a experiência estética está vinculada aquilo que denominamos por surpreendente. Entretanto, vale ressaltar que existem boas e más surpresas.

Segundo PEEZ (2005), a experiência estética apresenta características peculiares: "(...) se caracteriza pela experiência da descontinuidade e da diferença do que até então foi vivenciado, na qual durante o ato da percepção nos conscientizamos - ao mesmo tempo - de objetos dessa percepção" (p. 14). PEEZ salienta ainda: "Experiência estética se faz lá, onde a resistência e o inesperado com ajuda dos sentidos se torna objeto da consciência" (p. 29).

De tal forma, ao vivenciar aspectos como a alegria, o prazer ou mesmo o desapontamento e a crítica, o sujeito que dança emerge em circunstâncias de valor, muitas aditivadas pelo efeito surpreendente. E, é exatamente neste momento que a experiência de cunho estético se firma. Porém nem toda percepção consiste em uma experiência, visto que existe, ainda, uma condicionante à efetivação do processo, que é a qualificação ou reconhecimento do próprio sujeito como sendo este acontecimento ou momento significativo para a sua pessoa ou vida. Considerações dessa ordem também são importantes para aqueles que trabalham com a dança em caráter educativo. Visto que as atividades propostas para o corpo - sempre - irão integrar o banco de dados do "autoconceito do movimento" (QUITTEN, 1994) , o qual, por conseguinte, integrará as dimensões responsáveis pelo que denominamos como corporeidade.

\section{Conclusões}

Distintas são as definições e sentidos atribuídos ao espaço. Muitos deles criados pelo homem com a intenção de melhor compreender o ambiente em que habita. Com o presente estudo se buscou traçar um paralelo entre a dança e a espacialidade em acepção filosófica. Assim, por meio de analogias entre teorias de filósofos de diferentes correntes do pensamento se estabeleceu implicações para o entendimento da corporeidade do sujeito que dança. Neste contexto, observou-se que o sentido da espacialidade vai bem mais além da acepção geométrica ou matemática. Assim sendo, a definição de es- 
paço atribuída para aquele que dança não se limita a uma jurisdição imposta e circunscrita ao desempenho coreográfico do corpo, bem mais do que isto, o espaço da dança consiste em território à experimentação e materialização de peculiaridades existenciais. Diante disto, corpo e movimento foram notados como protagonistas da biografia de cada um de nós, logo, palcos à síntese de uma corporeidade.

Por fim, buscou-se aqui incentivar amantes e interessados pela dança a refletirem esta como um fenômeno vivido e percebido tanto externamente, como internamente ao corpo. Ler, escrever e pensar dança difere - em parte - da ação do dançar, no entanto, ao unir o corpo ao pensamento, tornando o próprio pensamento da dança uma dança pensante, acabou-se vivenciando esta no corpo do texto.

Referências Bibliográficas

ALÁRCON, Mónica; FISCHER, Mirian. Philosofie des Tanzes. Freiburg: Frauen e.V., 2006.

ALÁRCON, Mónica. Die Ordnung des Leibes- Eine Tanzphilosophische Betrachtung. Würzburg: Königshausen \& Neumann, 2009.

ARTUS, Hans-Gerd. Zu Struktur und Inhalt eines Studiengang Tanzwissenschaft. In: Jahrbuch Tanzforchung, vol. 4, 1993, p. 261-279.

BOURDIEU, Pierre. Sozialer Sinn. Kritik der theoretischen Vernunft. Frankfurt a.M.: Suhrkamp, 2003.

BRANDSTETTER, Gabriele; KLEIN, Gabriele. et al. (Org.). Methode der Tanzwissenschaft. Modellanalysen zu Pina Bauschs "Le Sacre du Printemps".

Bielefeld: Tanzscript, 2007.

COTTINGHAM, John. Descartes dictionary. Blackwell Reference. Oxford: Blackwell, 1993.

CSORDAS, Thomas. Embodiment and Experience. The Existential Ground of Culture and Self. Cambridge University Press, 1994.

CUNHA, José. Filosofia. Iniciação à Investigação Filosófica. São Paulo: Atual, 1992.

CURI, Rui, PROCOPIO, Joaquim. Fisiologia Básica. Rio de Janeiro: Guanabara Koogan, 2009.

DUPOND, Pascal. Vocabulário de Merleau-Ponty. Martins Fontes: São Paulo, 2010.

GOETHE, Johan Wolfgang von. Die Natur Fragment. In: Schriften zur Naturwissenschaft. Stuttgart, 1982.

GÜNZEL, Stephan. (Org.). Topologie. Bilefeld: Tanzkript, 2007, p. 13- 32. HEIDEGGER, Martin. Sein und Zeit. Max Niemeyer Verlag: Tübingen, 2006. HERMANN, Iris. Raum, Körper, Schrift. Bielefeld: IGEL, 1996.

HETZEL, Christoph. Der Leib als Subjekt der Bildung. Berlin: wvb, 2011. IMMENDÖRFER, Mirko. Der multisensuelle Raum: Prolegomena zum Bezugsverhältnis von Mensch, Raum und Technologie. Tese, Universidade de Siegen, 2005. 
JUNK, Vitor. Tanzwissenschaft. George Olms: Hildesheim, 1990.

KLEIN, Gabriele. Tanz in der Wissensgesellschaft. In: Gehm, S.; Husemann, P.; Wilcke, K, et al. (Org.). Wissen in Bewegung. Perspektiven der künstlerischen und wissenschaftlichen Forschung im Tanz. Bielefeld, 2007. p. 25-36.

LABAN, Rudolf von. Die Welt des Tänzers. Stuttgart: Seifert, 1992.

LENT, Robert. Cem Bilhões de Neurônios. São Paulo: Atheneu, 2010.

MERLEAU-PONTY, Maurice. Phänomenologie der Wahrnehmung. Berlin:

Gruyter, vol. 6, 1965.

NASCIMENTO, Marcelo de Maio. Tanz und Identität. 2007, Dissertação

(Doutorado)-Deutsche Sporthochschule Köln-Alemanha, 2007.

PEEZ, Georg. Evaluation ästhethischer Erfhrungs- und Bildungsprozesse. Bobingen: kopaed, 2005.

QUITTEN, Suzanne. Das Bewegungsselbstkonzept. Köln: Bps, 1994.Reichenbachs, H.; GIMBEL, Steven; WALZ, Anke. Writings on Space, Time and Motion.NY: Cambridge University Press, 2006.

REICHENBACHS, Hans; GIMBEL, Steven; WALZ, Anke. Writings on Space, Time and Motion. NY: Cambridge University Press, 2006.

SCHUBERT, Venanz. Erlebnis, Anschauung und Begriff des Raumes. In: Der Raum: Raum des Menschen - Raum der Wissenschaft. EOS-St. Ottilien, 1987. ULLMANN, Lisa. Domínio do Movimento. São Paulo: Summus, 1978. WESTPHAL, Kristin. Ertanzter Raum- Körper, Bewegung, Raum. In: L. Klepacki, E. Lieblau et all (Org). Tanzwelt. Münster:Waxmann, 2008, p. 45-63. YOKO, Arisaka. On Heidegger's Theory of Space: A Critique of Dreyfus. Inquiry 38:4. University of San Francisco. São Francisco-USA, Dezembro de 1995. p. 455-467. Disponível em: <http://www.arisaka.org/dreyfus.pdf>. Acesso em: 24.06.2013. 